\title{
Modernisasi (Studi pada Aktor Pertanian lahan basah Desa Samuda)
}

\author{
${ }^{1}$ Sigit Ruswinarsih, ${ }^{2}$ Reski $\mathbf{P}$ \\ ${ }^{12}$ Pendidikan Sosiologi, Fakultas Keguruan dan Ilmu Pendidikan, Universitas Lambung \\ Mangkurat \\ Email: reski@ulm.ac.id
}

\begin{abstract}
Modernization appears in various forms, both in tangible and unconscious forms. Modernization has gripped all sectors of human life without exception even in private spaces to public spaces, starting from technological modernization to modernization at the level of ideas. The aim is to find out the actions of farmers in Samuda village in responding to modernization in agriculture and constraints. This study used qualitative research methods. The technique for determining the informants used in this study was a purposive technique, which means that the researcher determines the informants based on qualifications that are in accordance with the research topic. Data collection techniques were carried out by observation, interviews, and documentation. The results showed that the actions of farmers in responding to modernization with the use of modern elements in agriculture. This modern element varies from one farmer to another, from one farmer group to another, from one land type to another. In tidal swamp farming, it is not possible to apply all the elements of agricultural renewal, but there are several factors such as land type, water conditions and weather that need to be considered before starting the farming process. Samuda farmers use a combination of agricultural tools in land management. At the stage of land cultivation, they use tractors if land conditions allow. In this case if the state of water is little and the soil is dry or little water. This consideration is important because tidal swamps are highly dependent on the high and low water conditions with land that is always flooded. During the dry season, the water discharge is low, so farmers can use tractors to cultivate the land.Based on the results of the research above, it is recommended that the government be more intensive in providing understanding and training for farmers regarding the use of modern tools in farming activities.
\end{abstract}

Keywords: Farmers, Modernization, Wetlands

\begin{abstract}
Abstrak
Modernisasi muncul dengan berbagai bentuk, baik dalam bentuk nyata hingga bentuk yang tanpa disadari. Modernisasi telah mencengkramsemua sektor kehidupan manusia tanpa terkecuali bahkan dalam ruang-ruang privat hingga ruang publik, dimulai dari modernisasi teknologi hingga modernisasi di tingkat gagasan. Tujuan untuk mengetahui tindakan petani desa Samuda dalam merespon modernisasi di bidang pertanian dan kendala. Penelitian ini menggunakan metode penelitian kualitatif. Adapun teknik penentuan informan menggunakan dalam penelitian ini dengan teknik purposive yang berarti peneliti menentukan informan berdasarkan kualifikasi yang sesuaidengan topik penelitian. Teknik pengumpulan data dilakukan dengan pengamatan, wawancara, dan dokumentasi. Hasil Penelitian menunjukkan bahwa Tindakan petani dalam mersepon modernisasi dengan penggunaan unsur-unsur modern dalam pertanian. Unsur modern ini bervariasi antara satu petani dengan petani lain, antara satu kelompok tani dengan kelompok tani lainnya, antara satu tipe lahan dengan tipe lahan lainnya. Pada pertanian rawa pasang surut tidak bisa serta merta menerapkan seluruh unsur-unsur pembaharuan pertanian namun ada beberapa faktor seperti tipe lahan, keadaan air dan cuaca yang perlu diperhatikan sebelum memulai proses bertani. Petani Samuda menggunakan kombinasi alat-alat pertanian dalam pengolahan lahan. Pada tahap pengolahan lahan, mereka menggunakan traktor jika kondisi lahan memungkinkan. Dalam hal ini jika keadaan air sedikit dan tanah dalam kondisi kering atau sedikit air. Pertimbangan ini penting karena rawa pasang surut sangat bergantung pada tinggi rendahnya keadaan air dengan lahan yang selalu tergenang air. Pada saat musim kemarau debit air sedikit maka petani bisa menggunakan traktor untuk mengolah lahan. Berdasarkan hasil penelitian di atas disarankan kepada pemerintah untuk lebih intensif lagi memberikan pemahaman dan pelatihan bagi para petani mengenai penggunaan alat-alat modern dalam kegiatan bertani.
\end{abstract}

Kata Kunci: Petani, Modernisasi, Lahan Basah

\section{PENDAHULUAN}

Indonesia mempunyai sebanyak 40,5 juta hektar lahan basah sehingga menjadikan Indonesia termasuk sebagai negara dengan jumlah lahan basah terluas di Asia Setelah China. Lahan basah umumnya merupakan wilayah yang sangat produktif dan memiliki keanekaragaman hayati bahkan non hayati, sehingga tidak mengherankan jika kemudian lahan basah dianggap salah satu sistem penyangga kehidupan yang begitu potensial (Kementerian Lingkungan Hidup, 2004). Hampir semua lahan basah yang ada dikelola menjadi areal pertanian maupun perkebunan (Rahmi, 2015) 
Salah satu daerah lahan basah terdapat di desa Samuda, Kabupaten Barito Kuala yang merupakan dataran rendah dan relatif datar dengan berada pada ketinggian 0,2-2 meter dpl yang kemampuan kesuburannya dipengaruhi oleh pasang surut air dan sebagian tergenang serta di dominasi rawa. Adapun luas wilayahnya yaitu 9,50 km yang mana, mayoritas pemanfaatan lahan sebagai area persawahan, maka tidak heran jika mayoritas penduduknya pada tahun 2019 yang berprofesi sebagai petani dengan jumlah 358 orang dan buruh tani sebanyak 28 orang (Profil Desa Samuda).

Petani menurut pendapat Anwas (Anwas, 1992) yaitu seseorang yang melakukan kegiatan bercocok tanam dari lahan pertaniannya sendiri atau bahkan memelihara ternak dengan maksud untuk memperoleh kehidupan dari kegiatanyang dilakukannya itu. Sebagai sebuah desa yang mayoritas penduduknya adalah petani, tentunya desa Samuda ini tidak terlepas dari arus modernisasi yang sedang berlangsung. Hal tersebut sejalan dengan apa yang diungkapkan oleh Martono bahwa tidak ada manusia yang luput dari "korban modernisasi" Modernisasi muncul dengan berbagai bentuk, baik dalam bentuk nyata hingga bentuk yang tanpa disadari. Modernisasi telah mencengkram semua sektor kehidupan manusia tanpa terkecuali bahkan dalam ruang-ruang privat hingga ruang publik, dimulai dari modernisasi teknologi hingga modernisasi di tingkat gagasan kini atau proses menuju masyarakat modern (Martono, 2011)

Hal tersebut seperti temuan penelitian yang diperoleh oleh Huttunen (Huttunen, n.d.) dengan judul "Revisiting agricultural modernisation: Interconnected farming practicesdriving rural development at the farm level" bahwa Most of the farmers had begun their farming careers with the clear idea of earning their income from agricultural production and actively developing the farm, which evolved as the core meanings of farming. Expansion andproduction maximisation are not purposes in themselves; however, for the farmers they became requirements for maintaining and increasing their income level, thus representing important meanings of farming practices (Huttunen, n.d.)). disisi lain, melihat kesiapan daripada buruh tani dalam menghadapi modernisasi yang tentu berita buruknya bukan tidakmungkin bisa mengancam eksistensi keberadaan mereka. Sehingga peneliti mengangkat judul "Aktor Pertanian Lahan Basah Menghadapi Modernisasi (Studi Pada Petani Dan Buruh Tani Di Desa Samuda, Barito Kuala)".

\section{METODE}

Penelitian ini menggunakan metode penelitian kualitatif sebuah prosedur penelitian yang menghasilkan data deskriptif dengan pendekatan yang diarahkan kepada latar dan individu secara utuh sehingga mendapatkan data yang alamiah berdasarkan perspektif individunya. Adapun teknik penentuan informan menggunakan dalam penelitian ini dengan teknik purposive yang berrati peneliti menentukan informan berdasarkan kualifikasi yang sesuai dengan topik penelitian. Dalam penelitian ini informan yang menjadi subjek penelitianadalah "Modernisasi (Studi pada Aktor Pertanian lahan basah Desa Samuda)". Berkaitan dengan sumber data, data yang langsung diperoleh dari informan adalah termasuk data primer. Selain data primer dalampenelitian ini diperlukan juga data sekunder yang dikumpulkan melalui teknik dokumentasi.

Teknik pengumpulan data dilakukan dengan pengamatan, wawancara, dan dokumentasi. Pengamatan dilakukan terhadap "Modernisasi (Studi pada Aktor Pertanian lahan basah Desa Samuda)". Wawancara terhadap Petani Dan Buruh Tani Di Desa Samuda, Barito Kuala dilakukandengan teknik wawancara semi terstruktur. Wawancara ini menggunakan panduan yangberisi garis besar pertanyaan penelitian, diharapkan pertanyaan akan berkembang sesuai dengan keadaan informan di lapangan. Melalui wawancara ini ditanyakan kepada informankeadaan sekarang dan masa lampau dan dapat dilacak pula halhal yang mungkin tersembunyi dalam diri informan (in-deept interview). Melalui tehnik dokumentasi dilakukan penelusuran dokumendokumen terkait dengan topik penelitian.

Klasifikasi analisa data menggunakan prosedur dari Miles dan Huberman (2000) yaitu tahap reduksi data, tahap penyajian data dan tahap penarikan kesimpulan. Pada tahap reduksi 
data dilakukan pemilahan data, mengkategorisasi data, dan merangkum data yang penting yang berkaitan dengan Petani Dan Buruh Tani Di Desa Samuda, Barito Kuala Padatahap penyajian data, peneliti mengorganisasikan dan menyusun data dalam suatu tulisan deskriptif sehingga dapat menguraikan temuan penelitian dengan jelas. Pada tahap penarikan kesimpulan, data yang sudah disajikan akan dianalisis sehingga terjadi elaborasi antara teori dan fakta yang terjadi di lapangan untuk mendapatkan kesimpulan akhir. Kesimpulan akhir dari keseluruhan aspek yang diteliti menjadi jawaban dari permasalahan penelitian. Kredibilitas data dilakukan dengan teknik triangulasi. Triangulasi yang akan dilakukan adalah triangulasi sumber, waktu dan triangulasi teknik.

\section{HASIL DAN PEMBAHASAN}

Desa samuda mayoritas penduduknya bekerja sebagai petani. Petani menurut pendapat Anwas (Anwas, 1992) yaitu seseorang yang melakukan cocok tanam dari lahan pertaniannya atau memelihara ternak dengan tujuan untuk memperoleh kehidupan dari kegiatan itu. Adapun menurut pendapat (Slamet, 2000), petani asli adalah petani yang memiliki tanah sendiri, bukan penyakap maupun penyewa. Petani asli misalnya seseorang mempunyai lahan sendiri, dikerjakan sendiri. Sedangkan yang bukan asli atau sering disebut petani "ketengan" hanya menyewa selama satu tahun, karena bukan tanah milik sendiri. Sebagai sebuah desa yang mayoritas penduduknya adalah petani, tentunya desa Samuda ini tidak terlepas dari arus modernisasi yang sedang berlangsung. Hal tersebut sejalan dengan apa yang diungkapkan oleh Martono (Martono, 2011) bahwa tidak ada manusia yang luput dari "korban modernisasi" Modernisasi muncul dengan berbagai bentuk, baik dalam bentuk nyata hingga bentuk yang tanpa disadari.

Unsur pertanian modern yang dipergunakan dalam pengelolaan lahan oleh petani Desa Samuda meliputi penggunaan alatalat pertanian, sistem irigasi, penggunaan bibit unggul, obat-obatan dan pupuk, serta pola tanam jajar legowo. Unsur modern ini bervariasi antara satu petani dengan petani lain, antara satu kelompok tani dengan kelompok tani lainnya, antara satu tipe lahan dengan tipe lahan lainnya. Pada pertanian rawa pasang surut tidak bisa serta merta menerapkan seluruh unsur-unsur pembaharuan pertanian namun ada beberapa faktor seperti tipe lahan, keadaan air dan cuaca yang perlu diperhatikan sebelum memulai proses bertani.

Berdasarkan penuturan petani bahwa ada tiga macam alsintan yang yang kerap digunakan dalam pertannian mereka. Diantara banyak alsintan, di Desa Samuda alat-alat yang dipergunakan dalam mekanisasi pertanian diantaranya adalah traktor, mesin perontok padi dan combine. Penggolongan alat pertanian oleh Jamaluddin, yaitu bahwa alat pertanian ari-ari digolongkan sebagai alat tradisional, arit/ celurit / sabit tergolong sebagai alat manual sedankan traktor, mesin perontok padi dan comben bisa dikategorikan sebagai alat mekanis atau modern (Jamaluddin, 2019)

Petani Samuda menggunakan kombinasi alat-alat pertanian dalam pengolahan lahan. Pada tahap pengolahan lahan, mereka menggunakan traktor jika kondisi lahan memungkinkan. Dalam hal ini jika keadaan air sedikit dan tanah dalam kondisi kering atau sedikit air. Pertimbangan ini penting karena rawa pasang surut sangat bergantung pada tinggi rendahnya keadaan air dengan lahan yang selalu tergenang air. Pada saat musim kemarau debit air sedikit maka petani bisa menggunakan traktor untuk mengolah lahan.

Pada saat lahan tergenang air maka alat yang digunakan adalah arit. Lahan dibersihkan dengan cara manual. Petani yang memiliki lahan yang luas maka mereka memerlukan tenaga buruh tani untuk membantu proses pengolahan lahan siap tanam ini. Namun sejak masuknya modernisasi, pembaharuan-pembaharuan dalam pengolahan lahan, selain penggunaan traktor maka banyak petani yang menggunakan obat untuk meluruhkan rumput-rumput yang tumbuh di lahannya. Cara ini dianggap lebih mudah dan murah dalam mempersiapkan lahan sebelum lanjut ke tahap penanaman.

Dalam hal pengairan pembaharuan dilakukan dengan adanya pengaturan air melalui irigasi pada persawahan yang menggunakan padi unggul. Di Desa Samuda tidak semua petani dapat menerapkan sistem pengairan irigasi ini. Pada kondisi lahan tipe A, petani mengandalkan 
pada pasang surut air, baik dari Sungai Barito maupun dari curah hujan tahunan. Lahan dengan tipe B lebih memungkinkan untuk menggunakan sistem irigasi. Di lokasi lahan dibuat saluransaluran irigasi sehingga pengairan bisa diatur, kapan lahan harus tergenang dan kapan harus kering. Hanya sedikit lahan pertanian di Desa Samuda yang memiliki saluran irigasi. Keadaan ini menyiratkan bahwa petani yang lebih punya kesempatan untuk bisa menggunakan alsintan seperti traktor dan mesin perontok hanyalah petani di lahan tipe B.

Dalam hal tanaman padi sebagai komoditas utama dalam pertanian masih menggunakan padi tahun atau padi lokal dan juga penggunaan bibit unggul atau disebut padi unggul. Dipandang dari sudut modernisasi, lahan pertanian dengan pengelolaan pengairan menggunakan sistem irigasi lebih memungkinkan untuk lebih maju dalam pertaniannya.

\section{KESIMPULAN}

Para petani sangat senang dengan hadirnya unsur modern dalam pengelolaan lahan pertanian. Kehadiran alat-alat pertanian membuat pengelolaan lahan menjadi lebih mudah. Waktu dan tenaga yang diperlukan dalam mengolah, memelihara tanaman sampai pada pemanenan menjadi lebih efektif. Demikian pula dengan biaya yang dikeluarkan untuk pengelolaan lahan menjadi lebih murah. Petani Samuda menggunakan kombinasi alat-alat pertanian dalam pengolahan lahan. Pada tahap pengolahan lahan, mereka menggunakan traktor jika kondisi lahan memungkinkan. Dalam hal ini jika keadaan air sedikit dan tanah dalam kondisi kering atau sedikit air. Pertimbangan ini penting karena rawa pasang surut sangat bergantung pada tinggi rendahnya keadaan air dengan lahan yang selalu tergenang air. Pada saat musim kemarau debit air sedikit maka petani bisa menggunakan traktor untuk mengolah lahan.

\section{SARAN}

Berdasarkan hasil penelitian di atas disarankan kepada pemerintah untuk lebih intensif lagi memberikan pemahaman dan pelatihan bagi para petani mengenai penggunaan alat-alat modern dalam kegiatan bertani.

\section{UCAPAN TERIMA KASIH}

Terima kasih kepada universitas lambung mangkurat yang telah memberikan dukungan dalam program dosen wajib meneliti (PDWM 2021) Sesuai SK Rektor Universitas Lambung Mangkurat Nomor: 697/UN8/PG/2021 Tanggal 22 Maret 2021.

\section{DAFTAR PUSTAKA}

Anwas, A. (1992). Pengantar Ilmu Pertanian. Rineke Cipta.

Huttunen. (n.d.). Revisiting agricultural modernisation: Interconnected farming practices driving rural development at the farm level. Journal of Rural Studies. journal homepage. Jurnal Ilmu Pertanian Indonesia (JIPI, 71, 36-47.

Jamaluddin. (2019). Alat dan Mesin Pertanian. Badan Penerbit UNM.

Martono, N. (2011). Sosiologi Perubahan Sosial. Rajawali Pers.

Rahmi. (2015). Pengelolaan Lahan Basah Terpadu di Desa Mulia Sari Kecamatan Tanjung. Jurnal Ilmu Pertanian Indonesia (JIPI), 20.

Slamet. (2000). Agrikultur. LPN-IPB-Bogor. 